\title{
A EVASÃO NO CURSO DE LICENCIATURA EM GEOGRAFIA OFERECIDO PELO
} CEFET-RN

\author{
Dante Henrique Moura \\ Professor Departamento de Formação de Professores do CEFET-RN - Doutor em Educação \\ dante@cefetrn.br \\ Meyrelândia dos Santos Silva \\ Licenciada em Geografia no CEFET-RN \\ meyrinha_s@yahoo.com.br
}

\begin{abstract}
RESUMO
O presente artigo se insere no contexto de uma pesquisa mais ampla que está sendo desenvolvida no âmbito do Núcleo de Pesquisa em Educação - NUPED - do CEFET-RN. A mencionada pesquisa visa estudar a evasão nos cursos de licenciatura oferecidos pela Instituição a fim de detectar suas causas e propor soluções para minimizá-las. Entretanto, o presente artigo circunscreve-se à Licenciatura em Geografia e busca identificar e explicitar as principais razões que levaram vários estudantes do curso a abandonar sua trajetória acadêmica. Dados oficiais da Instituição revelam que da primeira turma que ingressou na Licenciatura em Geografia, apenas 9 estudantes concluíram no tempo previsto (6 semestres), sendo que no início, a turma era composta por 30 estudantes. A partir desses dados, coletados mediante análise de documentos institucionais, partiu-se para o estudo das causas da evasão, tendo como base quatro categorias relacionadas com esse fenômeno, ou seja, questões que dizem respeito: à Instituição; aos professores do curso; à representação dos estudantes respeito à profissão docente; às condições socioeconômicas e aos interesses pessoais dos estudantes. A investigação desenvolveu-se a partir de uma pesquisa bibliográfica, além de entrevistas com os alunos evadidos e um questionário aplicado a alguns dos professores do curso. A partir da análise dos resultados, mediante triangulação de técnicas e instrumentos (aplicação de entrevistas e de questionários), assim como de sujeitos (estudantes e professores), concluiu-se que as principais razões da evasão nas turmas pesquisadas do curso de Licenciatura em Geografia oferecido pelo CEFET-RN estão relacionadas com a categoria condições socioeconômicas e interesses pessoais dos estudantes. Finalmente, as considerações finais incluem algumas sugestões para a Instituição minimizar o fenômeno da evasão.
\end{abstract}

PALAVRAS-CHAVE: Licenciatura em Geografia. Evasão. CEFET-RN.

\section{RESUMEN}

Este artículo fue producido como parte de una investigación más amplia que se está desarrollando en el ámbito del Núcleo de Pesquisa em Educação - NUPED - del CEFET-RN. La mencionada investigación visa estudiar la evasión en las licenciaturas ofrecidas por la Institución en aras de detectar sus causas y proponer soluciones de cara a subsanarlas. Sin embargo, el presente texto abarca exclusivamente la licenciatura en Geografía, buscando identificar y explicitar las principales razones que contribuyeron con la evasión de gran parte de sus estudiantes. Datos oficiales dan cuenta de que del primer grupo que ingresó en dicha licenciatura, tan solo 9 sacaron la carrera en el plazo previsto (6 semestres), siendo que 30 
habían empezado dicha carrera. A partir de esos datos, recolectados a través de análisis documental, se ha empezado a planificar el estudio de campo respecto a la evasión, adoptando como referencia 4 categorías relacionadas con ese fenómeno, es decir, cuestiones que dicen respecto a: la Institución; los profesores del curso; la representación que tiene los estudiantes respecto a la profesión docente; y las condiciones socioeconómicas y opciones personales de los estudiantes. El estudio se ha desarrollado a través de una investigación bibliográfica, de entrevistas con los alumnos evadidos y de una encuesta aplicada a los profesores de dicha licenciatura. El análisis de los datos recolectados, realizado a través de triangulación de técnicas e instrumentos (entrevistas y encuestas) y de sujetos (estudiantes y alumnos), ha permitido concluir que las principales razones de la evasión en los grupos de la Licenciatura en Geografía del CEFET-RN investigados, están relacionados con la categoría “condiciones socioeconómicas y opciones personales de los estudiantes”. Finalmente, las consideraciones finales incluyen algunas sugerencias en el sentido de que la Institución actúe de cara a mermar el grave problema que es la evasión.

PALABRAS CLAVE: Licenciatura en Geografía. Evasión. CEFET-RN. 


\section{A EVASÃO NO CURSO DE LICENCIATURA EM GEOGRAFIA OFERECIDO PELO CEFET-RN}

\section{INTRODUÇÃO}

O presente artigo se insere no contexto de uma pesquisa mais ampla que está sendo desenvolvido no âmbito do Núcleo de Pesquisa em Educação - NUPED - do CEFET-RN. Esse Núcleo iniciou suas atividades em 2004 e, atualmente, realiza estudos nas linhas de pesquisa: Currículo, Gestão e avaliação; Formação docente; e Educação de jovens e adultos integrada à educação profissional.

A mencionada pesquisa visa estudar a evasão nos cursos de Licenciatura em Física e em Geografia oferecidos pelo CEFET-RN ${ }^{1}$ a fim de detectar suas causas e propor soluções para minimizá-las. O projeto ainda não foi concluído, mas já existem elementos relativos à Licenciatura em Geografia que explicam as principais razões que levaram vários estudantes do curso a abandonar sua trajetória acadêmica, conforme discutido na monografia de conclusão de curso intitulada Investigando a Evasão no Curso de Licenciatura em Geografia Oferecido pelo CEFET-RN (SILVA, 2008).

Como dado introdutório à problemática em análise, importa esclarecer que as atividades acadêmicas da Licenciatura em Geografia do CEFET-RN foram iniciadas no segundo semestre de 2002. Na primeira turma ingressaram 30 estudantes, de acordo com os dados da Coordenadoria de Registros Acadêmicos (CRA). Desses, apenas 9 concluíram o curso dentro da duração prevista (6 semestres), ou seja, em 2005.2.

Evidentemente, alguns concluíram o curso posteriormente, mas, ainda assim, foi elevada a evasão. Os dados dos semestres seguintes permanecem muito tímidos com relação ao número de concluintes. Assim sendo, em 2006.1, segundo período em que houve conclusão nas Licenciaturas, apenas 6 estudantes se graduaram nessa licenciatura.

Ainda de acordo com a CRA, desde o início do curso (2002.2), ingressaram cerca de cento e cinqüenta alunos, sendo que somente 45 concluíram o curso e, dentre esses, apenas 25 requisitaram o diploma até novembro de 2007.

Essa situação exige a investigação das raízes desse problema. Não se pode naturalizar algo que não o é. Principalmente quando se trata de elevada evasão em oferta pública e gratuita de educação superior em um país no qual apenas a minoria da população chega a esse nível educacional. Nesse sentido, convém explicitar que, atualmente, a taxa bruta de escolarização na educação superior no país é de $20 \%$ e a líquida de $12 \%$ (BRASIL, 2007) ${ }^{2}$. Além disso, a grande maioria dessa matrícula está nas instituições privadas de educação superior $(74,1 \%$,

${ }^{1}$ O CEFET-RN também oferece uma Licenciatura em Espanhol. Entretanto, esse curso não está inserido no âmbito da referida pesquisa porque, em 2007.1, semestre em que se iniciou o estudo, essa licenciatura só contava com a turma, que estava no segundo período.

${ }^{2}$ A Taxa de Escolarização Bruta na Educação Superior é a razão entre a matrícula total na educação superior (ensino de graduação), independentemente da idade dos alunos matriculados, e a população na faixa etária 18 a 24 anos. A Taxa de Escolarização Líquida na Educação Superior é a razão entre a matrícula na educação superior (ensino de graduação) da população com idade compreendida entre 18 e 24 anos e a população nessa mesma faixa etária. 
segundo o Censo da Educação Superior 2006/INEP), de maneira que a absoluta maioria do universo de estudantes da educação superior está pagando pelo que deveria ser um direito social.

Diante do exposto, assume-se como objetivo geral deste artigo, identificar e analisar as principais causas da evasão no curso de Licenciatura em Geografia oferecido pelo CEFETRN.

\section{PERCURSO METODOLÓGICO E PROCEDIMENTOS}

Para alcançar o objetivo delineado, inicialmente, foi feita uma busca e análise de documentos relativos ao tema em questão e uma revisão bibliográfica para fundamentar o trabalho. Nessa fase, também foram coletados os dados quantitativos inerentes ao fluxo dos estudantes da Licenciatura em Geografia do CEFET-RN. Em seguida, elaborou-se um roteiro básico para dar suporte às entrevistas semi-estruturadas realizadas com os estudantes que haviam interrompido definitivamente suas trajetórias acadêmicas na Licenciatura em Geografia do CEFET-RN.

A entrevista foi escolhida como técnica de coleta de dados porque, segundo Lakatos (2003), trata-se de uma conversação efetuada face a face, de maneira metódica, que pode proporcionar resultados satisfatórios e informações necessárias. Por meio da entrevista pode-se conhecer o significado que o entrevistado dá aos fenômenos e eventos de sua vida, utilizando seus próprios termos. Essa técnica permite a coleta de dados importantes que não se encontram em fontes documentais e nem podem ser coletados por meio de outra técnica ou instrumento.

Os estudos preliminares permitiram identificar quatro categorias como possíveis causas da evasão, as quais foram incorporadas ao roteiro que deu suporte às entrevistas: aspectos relacionados com a Instituição, como horário do curso, matriz curricular, mudança no currículo e sistema de avaliação; questões relacionadas aos professores, como a relação professor e aluno e estilo do professor, que podem ter influenciado para a saída do aluno; $a$ representação dos estudantes em relação à profissão docente em Geografia; identificação com a carreira de professor e a visão do aluno sobre a profissão em si; questões relacionadas com as condições socioeconômicas e interesses pessoais dos estudantes, como falta de motivação para estudar, motivo da escolha do curso, dificuldade de locomoção para a instituição, despesas exigidas por um curso superior, as quais, de acordo com os estudos realizados, podem estar relacionadas às causas dessa evasão.

Esse roteiro foi elaborado no âmbito do NUPED e serviu de base para a coleta de dados dos estudantes evadidos da Licenciatura em Geografia e em Física. O instrumento foi elaborado, inicialmente, nos encontros realizados periodicamente entre o orientador da pesquisa e os estudantes-pesquisadores e, posteriormente, passou por um processo de validação realizado pelo orientador e por outra pesquisadora do CEFET-RN, que também é membro do NUPED.

Tendo em vista o elevado número de estudantes, pois seis turmas estão em atividade, foi definida uma amostra composta por duas turmas: uma que iniciou o curso em 2004.2 e outra que começou suas atividades em 2006.1 (a partir de agora identificadas por Turma A e Turma 
$B$, respectivamente). Essas turmas foram escolhidas porque uma delas foi a última do currículo em extinção (Turma A), e a outra por ser a primeira turma após a mudança de Plano de Curso (Turma B).

Inicialmente, previu-se que as entrevistas seriam realizadas com vinte estudantes, sendo dez de cada turma. Após a escolha dessa amostra foi estabelecido um contato prévio, por via telefônica, com os ex-alunos a partir de informações proporcionadas pelo Departamento Acadêmico de Formação de Professores (DAFOP). Nem todos os contatos resultaram em entrevistas. Algumas vezes, em função da ausência do estudante de sua residência e outras por mudanças do número telefônico. Outra dificuldade foi a falta de horário por parte dos informantes, o que acabava resultando na recusa. A maioria trabalhava e estudava, de maneira que alguns não tiveram tempo disponível para a entrevista. Entretanto, a recusa não foi generalizada e o que predominou foi um grande interesse em falar sobre a(s) causa(s) que os levaram a abandonar o curso. Em função das dificuldades mencionadas, foi necessário reduzir a amostra de dez para cinco estudantes por turma, o que não resultou em prejuízos à investigação já que esse número corresponde a quase 15\% do total de estudantes de cada turma, ou seja, um percentual bem maior quando consideram-se apenas os evadidos.

Após esses procedimentos iniciais, iniciou-se o processo de realização das entrevistas, as quais foram gravadas em MP3 e logo após transcritas para viabilizar uma melhor análise das falas dos entrevistados.

Como as entrevistas foram semi-estruturadas, as perguntas foram realizadas a partir das categorias definidas no roteiro previamente elaborado, entretanto os informantes foram sistematicamente informados de que tinham total liberdade para falar sobre qualquer outro tema não contemplado nas categorias prévias e que, na visão deles, pudesse ter contribuído para o abandono do curso.

Com o objetivo de realizar a triangulação de sujeitos e de técnicas/instrumentos, também foram ouvidos professores do curso a respeito das causas da evasão dos estudantes. A eles foi aplicado um questionário, também construído e validado no âmbito do NUPED. O questionário foi elaborado após a análise das entrevistas concedidas pelos estudantes, de maneira que os professores só foram questionados a respeito de temas que os estudantes já haviam considerado como causas significativas de evasão, garantindo assim o contraste de informações de distintas fontes.

Juntamente com o questionário foi enviada uma nota explicando o motivo e a natureza da pesquisa, sua importância e a necessidade de obter respostas, com o intuito de despertar interesse no recebedor, no sentido de que preenchessem e devolvessem o instrumento no prazo necessário.

A escolha dos professores recaiu sobre aqueles que lecionaram nas turmas investigadas no semestre em que ocorreu a maior taxa de evasão. Assim, foi identificado, a partir dos dados institucionais, que na Turma A, foi no $2^{\circ}$ período (2005.1) que ocorreu a maior incidência de evasão - 07 sujeitos ou $23 \%$-; e na Turma B, o fenômeno foi observado do $3^{\circ}$ período (2007.1) - 11 sujeitos ou 41\% -. De posse desses dados, buscou-se informação sobre quais professores haviam lecionado nos mencionados semestres e continuavam na Instituição. Em 
seguida, foram estabelecidos os contatos no sentido de identificar os que tinham disponibilidade e interesse em participar da pesquisa.

Após a análise dos resultados, mediante triangulação das informações dos estudantes e dos professores, foram realizadas as considerações finais, que incluem sugestões para a Instituição minimizar o problema da evasão.

\section{A EVASÃO NAS LICENCIATURAS}

A evasão escolar no ensino superior brasileiro é um fenômeno grave que acontece tanto nas instituições públicas quanto nas privadas e requer medidas eficazes de combate. Gaioso (2005) afirma que a partir de 1972, o Ministério da Educação/MEC e as universidades públicas manifestaram preocupações com o assunto, o que ocasionou o surgimento de alguns estudos. Conseqüentemente, informações estatísticas vieram a público indicando o relevante número de desistentes nesses cursos.

No presente estudo, compreende-se a evasão como um fenômeno complexo e que, portanto, não pode ser considerado de forma linear para todos os sistemas, instituições, ofertas educacionais ou sujeitos. O termo evasão é muito carregado de um sentido que culpabiliza o indivíduo que, por várias razões, interrompeu definitivamente sua trajetória em uma determinada oferta educacional. Dessa forma, o termo também contribui para isentar a instituição e o respectivo sistema educacional de qualquer responsabilidade sobre esse fenômeno. É preciso ter claro que o afastamento definitivo de um estudante de determinada oferta educacional é fruto de múltiplos fatores sociais, econômicos, familiares, institucionais e pessoais, os quais se reforçam mutuamente e resulta na chamada evasão.

Nesse sentido, Rozentraten (1992,) citado por Gaioso (2005), enfatiza que algumas profissões incluem traços altamente valorizados, como Direito, Engenharia e Medicina e geram expectativas de altos salários, emprego garantido, inteligência elevada, dificuldade nos estudos e riqueza. Outras, como as decorrentes das licenciaturas, são marcados pela falta de prestígio social que leva à redução na demanda nos vestibulares, pois as atividades profissionais não são social e economicamente bem reconhecidas; são vinculadas a salários menores e à falta de garantia de emprego, resultando em que os estudantes que se preparam para tais carreiras tenham maiores probabilidades de optarem pela evasão.

De acordo com o conselheiro da Câmara de Educação Básica (CEB) do Conselho Nacional de Educação (CNE), Antonio Ibañez Ruiz, a evasão nos cursos de Licenciatura nas universidades de todo o país é excessivamente alta, e por vários fatores, que vão desde as repetências sucessivas nos primeiros anos, até a falta de recursos para os alunos se manterem, mesmo numa universidade pública.

Um estudo, realizado em 2000, pela Universidade de Mato Grosso - UFMT - destaca que os cursos de Bacharelado apresentam um quadro otimista, representado pela absorção e expansão de espaços no mundo do trabalho, enquanto as licenciaturas apresentam um quadro diferenciado, representado, principalmente, pela desvalorização da carreira do magistério. 
Um estudo de 1997 realizado pela Comissão Especial de Estudos sobre a Evasão nas Universidades Públicas Brasileiras, feito em regime de colaboração entre o MEC e o Fórum de Pró-Reitores de Graduação (FORGRAD), mostra o percentual de evasão nas licenciaturas, conforme é demonstrado na Tabela 01.

Tabela 01 - Evasão nos cursos de Licenciatura

\begin{tabular}{|c|c|}
\hline Curso & Percentual de Evasão \\
\hline Licenciatura em Matemática & $56 \%$ \\
\hline Licenciatura em Química & $75 \%$ \\
\hline Licenciatura em Física & $65 \%$ \\
\hline Licenciatura em Biologia & $42 \%$ \\
\hline Licenciatura em História & $44 \%$ \\
\hline Licenciatura em Geografia & $\mathbf{4 7 \%}{ }^{\mathbf{3}}$ \\
\hline Licenciatura em Letras & $50 \%$ \\
\hline Licenciatura em Educação Artística & $52 \%$ \\
\hline
\end{tabular}

Fonte: MEC / INEP / CAPES, 1997.

Enquanto isso, o país se debate com uma grande falta de professores em sala de aula. Dados do INEP (1998) revelaram que em 1997 havia um déficit de cerca de 240.000 postos docentes somente nas esferas que compreendem o Ensino Fundamental e o Ensino Médio (hoje esse número ultrapassa os 245 mil). À época, o número total de funções docentes ocupadas ultrapassava a cifra de 1 milhão, nessas etapas educacionais.

Sabe-se que o desejo de titulação superior está fortemente associado à busca de melhoria da qualidade de vida e estabilidade financeira, embora nem sempre isso aconteça. Gomes (1998), citado por Gaioso (2005, p.15), enfatiza que

o desejo de cursar a educação superior está intensamente vinculado a projetos de ascensão social e a bons salários. Quando esses projetos não se viabilizam na área escolhida, como é o caso do magistério, o aluno tende a abandonar o curso de licenciatura em busca de outro mais valorizado socialmente.

Os problemas enfrentados pelos futuros professores durante a vida acadêmica são desestimulantes e provocam, na maioria das vezes, a evasão, complementa o mesmo autor.

Em relação ao Rio grande do Norte, a Universidade Federal do Rio grande do Norte, também apresenta números elevados de evasão, principalmente na área das licenciaturas.

De acordo com os dados da Coordenação de controle e avaliação da Pró-Reitoria de Planejamento - PROPLAN -, em quatro anos foram mais de dois mil alunos evadidos na UFRN, dos quais, mais de 500 são do Centro de Ciências Humanas, Letras e Artes, onde se encontram as licenciaturas (Tabela 02).

\footnotetext{
${ }^{3} \mathrm{O}$ negrito foi introduzido pelos autores do presente texto
} 
Tabela 02 - Evolução da evasão no período de 2003 a 2004 nos cursos do Centro de Ciências Humanas, Letras e Artes.

\begin{tabular}{|l|c|c|c|c|c|}
\hline Curso Ano & $\mathbf{2 0 0 3}$ & $\mathbf{2 0 0 4}$ & $\mathbf{2 0 0 5}$ & $\mathbf{2 0 0 6}$ & $\begin{array}{c}\text { Total de } \\
\text { perdas }\end{array}$ \\
\hline Artes Visuais & - & - & - & 1 & 1 \\
\hline Ciências Sociais & 15 & 15 & 17 & 20 & 67 \\
\hline Com. Social & 9 & 7 & 15 & 15 & 46 \\
\hline Educação Artística & 13 & 6 & 18 & 23 & 60 \\
\hline Filosofia & 7 & 9 & 10 & 15 & 41 \\
\hline Geografia & 3 & 12 & 14 & 17 & 46 \\
\hline História & 22 & 31 & 51 & 52 & 146 \\
\hline Letras & 17 & 12 & 18 & 23 & 70 \\
\hline Psicologia & 9 & 28 & 15 & 16 & 65 \\
\hline \multicolumn{1}{|c|}{ TOTAL } & $\mathbf{9 5}$ & $\mathbf{1 2 0}$ & $\mathbf{1 5 8}$ & $\mathbf{1 8 2}$ & $\mathbf{5 5 5}$ \\
\hline
\end{tabular}

Fonte: Coordenação de controle e avaliação/PROPLAN/UFRN

Assim, é imperativo reconhecer que esta é uma área profissional que se tem mostrado cada vez menos atraente, tanto pelas condições de formação oferecidas pelos cursos em si, quanto pelas condições em que seu exercício se dá, além das condições salariais, a desvalorização profissional, a imagem social ambígua e a baixa auto-estima de muitos professores.

\section{A LICENCIATURA EM GEOGRAFIA NO CEFET-RN}

Na graduação, o CEFET-RN oferece atualmente, além dos cursos superiores de Tecnologia, três cursos voltados para a formação de professores: as licenciaturas em Geografia, em Física e em Espanhol, sendo que os cursos de Geografia e de Física foram criados em 2002 e o de Espanhol em 2006.

Essa inserção das licenciaturas no CEFET-RN foi devido, em parte, ao grande déficit de professores licenciados observado no sistema educacional, conforme mencionado anteriormente.

Daí surge a necessidade de ampliar o número de professores licenciados para atuar nos Ensinos Fundamental e Médio. Uma das iniciativas do MEC foi convidar os CEFETs a participarem de um esforço nacional de formação docente, já que essas instituições tinham poucas ou nenhuma oferta nesse nível educacional, pois a maioria dos cursos de graduação eram cursos Superiores de Tecnologia ${ }^{4}$. O projeto político-pedagógico do CEFET-RN ratifica que a Instituição, assim como toda Rede Federal de Educação Profissional e Tecnológica, vem ampliando e diversificando substancialmente sua oferta formativa. Nesse contexto,

em pouco tempo a Instituição deixou de atuar, quase exclusivamente, na formação de técnicos de nível médio para operar nos níveis básico, técnico e tecnológico da educação profissional, no ensino médio, na formação de professores e, inclusive, na pós-graduação lato sensu. (CEFET-RN, 2003, p. 4)

\footnotetext{
${ }^{4} \mathrm{O}$ processo que resultou na entrada dos CEFETs na oferta de curso de licenciatura é extremamente complexo e resultante de interesses diversos e, muitas vezes, conflitantes. Entretanto, não é objetivo deste artigo analisá-lo. Para um maior aprofundamento sobre esse processo sugere-se ver Bonfim (2004).
} 
O curso de Licenciatura em Geografia foi criado, inicialmente, a partir dos seguintes elementos que fundamentaram a justificativa: demanda existente de professores de Geografia da rede pública e privada que atuam sem o curso de Licenciatura; número crescente de matrícula de alunos na Educação Básica, especificamente nos dois últimos ciclos do Ensino Fundamental e no Ensino Médio; carência de professores de Geografia nas redes estadual e municipal; mudanças de paradigmas, novo contexto socioeconômico e novas tecnologias, exigindo um novo fazer pedagógico. (CEFET-RN, 2002, p.11)

O Plano desse Curso, que ainda encontrava-se em fase de reconhecimento, possuía as seguintes características: duração prevista de três anos; presencial, com possibilidade de ser oferecido, posteriormente, também na modalidade Educação à Distância; matriz curricular com 3.424 horas/aula (2.568 h), sendo 800 de Estágio Supervisionado de Ensino, distribuídos ao longo do curso; e funcionava no horário de 18h15min às 22h15min. O curso habilitava profissionais para atuar como docentes da Educação Básica, prioritariamente no Ensino Médio.

Apresentava uma estrutura modular composta de base científica e tecnológica geral e base científica e tecnológica específica, enquanto recortes do conhecimento. Contemplava os princípios da flexibilidade, verticalização (expresso nos recortes de conhecimentos ampliadores), contextualização, interdisciplinaridade e transdisciplinaridade do ensino, numa perspectiva filosófica da complexidade do conhecimento. Fundamentado em um currículo para o desenvolvimento de competências. (CEFET-RN, 2002, p. 30)

O horário de funcionamento do curso, assim como uma elevada carga horária semanal, já que eram apenas três anos, implicava em muitas disciplinas por semestre, causando insatisfação nos alunos, principalmente naqueles que trabalhavam o dia todo e tinham dificuldades em chegar no horário de início das aulas.

Diante desse quadro, no processo de Redimensionamento do Projeto Político-Pedagógico (RPPP) do CEFET-RN, iniciado em 2004, decidiu-se (re)construir o Plano de Curso, assim como o da Licenciatura em Física. Esse processo visou contribuir para a formação do professor de Geografia de forma integral. Para isso, ampliou-se a duração do curso de três para quatro anos, foi redimensionada a distribuição da carga horária e o número de disciplinas oferecidas por semestre, além do horário das aulas, que passaram a acontecer das 19 às 22h com o intuito de contribuir a permanência dos alunos trabalhadores no curso.

Buscou-se, cada vez mais, a integração entre os conhecimentos didático-pedagógicos e os específicos da Geografia em um conjunto coeso e interdisciplinar, respeitando não só as mudanças de paradigmas, como também o novo contexto socioeconômico e as novas tecnologias que exigem do professor um novo fazer pedagógico. (CEFETRN, 2006, p7)

A matriz curricular do curso está organizada por disciplinas em regime seriado semestral, distribuída em três núcleos: específico; complementar; e didático- pedagógico. Além disso, compõe a matriz uma carga horária destinada à Prática como Componente Curricular, assim como o Estágio Curricular Supervisionado e as Atividades Acadêmico-Científico-Culturais, totalizando uma carga horária de 2.875 horas. 
A prática como componente curricular deve ser vivenciada no decorrer do curso num total de 400 (quatrocentos) horas, permeando todo o processo de formação do geógrafo-educador numa perspectiva interdisciplinar, contemplando as dimensões teórico-práticas. . (CEFET-RN, 2006, p.13).

Além disso, são desenvolvidos projetos integradores do $3^{\circ}$ ao $6^{\circ}$ período, os quais têm o objetivo de articular teoria e prática, valorizando a pesquisa individual e coletiva, funcionando como espaço interdisciplinar na formação dos futuros professores. A interdisciplinaridade surge como uma tentativa de romper o percurso atual de fragmentação dos objetos do conhecimento nas diversas áreas, através da contrapartida do incremento de uma visão de conjunto do saber instituído.

Assim, nesses períodos os estudantes têm horários de aula nos quais, com a orientação de professores, desenvolvem estudos acerca da construção de projetos que integrem os conhecimentos relativos às disciplinas estudadas no semestre em curso. Posteriormente, no $7^{\circ}$ e $8^{\circ}$ períodos o aluno desenvolverá a respectiva Monografia de final de curso, podendo verticalizar os conhecimentos construídos nos projetos integradores. Da mesma forma que nos projetos integradores, o aluno terá momentos de orientação e tempo destinado à elaboração da respectiva monografia, de forma que totalizará às 400 horas de prática como componente curricular do $3^{\circ}$ ao $8^{\circ}$ período. (CEFET-RN, 2006, p.13)

Nesses primeiros semestres de implementação dos projetos integradores no novo plano da Licenciatura em Geografia se estão detectando dificuldades em fazer a transposição da teoria à prática desses projetos, apesar da grande importância dessa metodologia de trabalho acadêmico para a formação docente. Os alunos alegam não ter tempo para se dedicar ao projeto, pois o mesmo requer preparação e planejamento para que possam ser executados de forma satisfatória. Se exige um empenho coletivo da turma, o que infelizmente muitas vezes não acontece. Por outro lado, os professores também encontram dificuldades em planejar e trabalhar coletivamente, pois essa não é a tradição que predomina na profissão docente, fruto da formação disciplinar que orienta a maioria dos currículos dos cursos de licenciatura do país (assim como das demais graduações). Assim sendo, é necessário romper esse ciclo no qual o professor não trabalha de forma coletiva e interdisciplinar porque foi aprendeu a profissão em uma escola disciplinar e compartimentalizada, reproduzindo essa maneira de trabalhar ao formar outra geração de professores, perpetuando a situação que aprisiona os conhecimentos disciplinares em si mesmos, isolando-os das outras disciplinas. Diante desse quadro, os projetos integradores representam uma possibilidade (não a única) de contribuir para romper com esse isolamento, de maneira que requer um maior esforço de professores, estudantes e gestão para a sua consecução, na prática.

Apesar de algumas dificuldades, a Licenciatura em Geografia do CEFET-RN é um curso muito bem conceituado, pois em seu processo de reconhecimento, por ocasião da conclusão da primeira turma, o curso recebeu conceito B do MEC, em 2005. Além disso, no mesmo ano seus estudantes participaram pela primeira vez do Exame Nacional de Desempenho dos Estudantes - ENADE - obtendo pontuação máxima e colocando-se entre os três cursos mais bem avaliados no país. 
Em suma, o Curso Superior de Licenciatura em Geografia tem por objetivo geral formar profissionais capazes de compreender os processos referentes à produção e reprodução do espaço geográfico bem como atuar no processo ensino-aprendizagem no âmbito do ensino fundamental e do ensino médio. Igualmente, objetiva oferecer orientação filosófica, teórica e metodológica para a análise geográfica, possibilitando a reflexão sobre os principais fenômenos espaciais que compõem a realidade geográfica em suas múltiplas escalas de análise. Simultaneamente, busca propiciar o desenvolvimento de projetos pesquisas, bem como a produção de conhecimentos na área da Geografia e da Educação de forma integrada. (CEFETRN, 2006, p.8)

\section{A EVASÃO NA LICENCIATURA EM GEOGRAFIA DO CEFET-RN E SUAS CAUSAS}

Como já mencionado anteriormente, foram escolhidas duas turmas para serem analisadas em relação à evasão: Turma A, última do currículo em extinção; e a Turma B, a primeira após a mudança no Plano de Curso.

No semestre letivo de 2004.2 iniciaram trinta e sete alunos, sendo que desses, trinta e um possuíam matricula 2004.2 (Turma A), os demais eram remanescentes de turmas anteriores, os quais estavam desnivelados. No semestre seguinte, 2005.1, a Turma A contava com 24 alunos com matricula 2004.2, pois 7 já haviam abandonado o curso em 2004.2. Ao longo de 2005.1 a turma teve 5 evadidos, passando a contar com apenas 19 estudantes no início de 2005.2. Nesse terceiro semestre (2005.2) ocorreram 3 evasões, de maneira que apenas 16 alunos com matricula 2004.2. iniciaram 2006.1, sendo que um deles abandonou o curso durante esse semestre. No penúltimo semestre (2006.2) 2 estudantes se afastaram definitivamente do curso, de forma que apenas 13 iniciaram o período letivo 2007.1.

A seguir, apresenta-se Tabela 3, que é uma síntese do fluxo dos estudantes da Turma A desde o $1^{\circ}$ período do curso (2004.2) até o último (2007.1).

Tabela 03 - Fluxo dos estudantes da Turma A entre os períodos letivos 2004.2 e 2007.1

\begin{tabular}{|c|c|c|c|c|c|c|}
\hline \multirow{2}{*}{$\begin{array}{c}\text { Período } \\
\text { letivo/semestre }\end{array}$} & \multicolumn{2}{|c|}{ Matrícula inicial } & \multicolumn{2}{c|}{ Evadidos } & \multicolumn{2}{c|}{ Evasão acumulada } \\
\cline { 2 - 7 } & Quantidade & $\mathbf{\%}$ & Quantidade & \% & Quantidade & \% \\
\hline $1^{\mathbf{0}}(2004.2)$ & 31 & 100 & 7 & 22,6 & 7 & 22,6 \\
\hline $2^{\mathbf{0}}(2005.1)$ & 24 & 77,4 & 5 & 16,1 & 12 & 38,7 \\
\hline $3^{\mathbf{0}}(2005.2)$ & 19 & 61,3 & 3 & 9,7 & 15 & 48,4 \\
\hline $4^{\mathbf{0}}(2006.1)$ & 16 & 51,6 & 1 & 3,2 & 16 & 51,6 \\
\hline $5^{\mathbf{0}}(2006.2)$ & 15 & 48,4 & 2 & 6,5 & 18 & 58,1 \\
\hline $6^{\mathbf{0}}(2007.1)$ & 13 & 41,9 & - & - & - & - \\
\hline
\end{tabular}

Percebe-se que a maior evasão ocorreu na mudança do $1^{\circ}$ para o $2^{\circ}$ semestre (07 evadidos), mas que esse fenômeno continuou ao longo dos demais semestreso. Esses dados vão ao encontro do levantamento feito pelo Núcleo de Apoio aos Estudantes de Graduação - NAEG ligado à pró-reitoria de graduação da Universidade de São Paulo - USP, o qual acompanhou a trajetória de 27.789 alunos ingressantes em 131 cursos de graduação nos anos de 1995 a 1998 e mapeou a evasão. Em 1995, de um total de 2.366 desligamentos, 56,1\% foram no primeiro semestre. Em 1998, dos 1.626 alunos que abandonaram o curso, 44,3\% o fizeram também no primeiro semestre. 
Após a mudança no Plano do Curso, uma nova turma iniciou seus estudos em 2006.1 (Turma B), composta por 33 alunos, todos com matricula 2006.1. No segundo semestre (2006.2), dos 33 alunos que haviam entrado em 2006.1, 27 permaneceram, sendo que 11 se evadiram ao longo de 2006.2. Assim sendo, em 2007.1, terceiro semestre do curso, apenas 16 continuavam matriculados, ou seja, mais da metade de alunos já haviam abandonado o curso antes do quarto semestre de um total de 8 . Na Tabela 4 apresenta-se o fluxo dos estudantes da Turma B entre os períodos 2006. 1 e 2007.1

Tabela 04 - Fluxo dos estudantes da Turma A entre os períodos letivos 2004.2 e 2007.1

\begin{tabular}{|c|c|c|c|c|c|c|}
\hline \multirow{2}{*}{$\begin{array}{c}\text { Período } \\
\text { letivo/semestre }\end{array}$} & \multicolumn{2}{|c|}{ Matrícula inicial } & \multicolumn{2}{c|}{ Evadidos } & \multicolumn{2}{c|}{ Evasão acumulada } \\
\cline { 2 - 7 } & Quantidade & $\mathbf{\%}$ & Quantidade & $\mathbf{\%}$ & Quantidade & \% \\
\hline $1^{\circ}(2006.1)$ & 33 & 100 & 6 & 18,2 & 6 & 18,2 \\
\hline $2^{\circ}(2006.2)$ & 27 & 81,8 & 11 & 33,3 & 17 & 51,5 \\
\hline $3^{\circ}(2007.1)$ & $16^{5}$ & 48,5 & & & & \\
\hline
\end{tabular}

A comparação entre as tabelas 3 e 4 permite concluir que mesmo após a mudança no Plano de Curso a evasão ainda continua muito intensa na Licenciatura em Geografia oferecida pelo CEFET-RN, apesar dessa mudança ter produzido outras melhorias no Curso, como avanços na estrutura, na organização e no seu funcionamento de uma forma geral.

A análise dos dados proporcionados pelos sujeitos da pesquisa permitiu concluir que dentre as categorias de análise adotadas, ou seja, questões relativas: à Instituição; aos professores do curso; à representação dos estudantes em relação à profissão docente; as condições socioeconômicas e interesses pessoais dos estudantes, a última é a que maior relação tem com a evasão dos estudantes das turmas A e B. Apesar disso, a representação dos licenciandos acerca da profissão docente (Turma A) e alguns problemas relacionados com o CEFET-RN (Turma B) também influenciaram no fenômeno estudado. Enquanto isso, a categoria professores do curso não foi citada como um motivo para o abandono.

Em seguida serão apresentadas algumas vozes dos sujeitos investigados que ratificam as afirmações acima. Em relação à Instituição, quando foram indagados se houve algum problema em relação ao CEFET-RN, no primeiro momento mencionram

Não. Do ponto de vista da Instituição não. Eu gostava muito do curso, eu achava que era um curso muito bom, que não deixava nada a desejar... acerca do nível da Instituição não, porque o CEFET é uma instituição muito legal também.”(Entrevistado 01- Turma B)

Entretanto, no decorrer da entrevista alguns se queixaram do regime de matrícula, que não é por crédito, mas seriado semestral. Dois dos sujeitos afirmaram que se o sistema não fosse assim eles teriam continuado o curso. Um deles disse

\footnotetext{
${ }^{5}$ Conforme explicitado anteriormente, a coleta de dados foi realizada no semestre 2007.1 em função do cronograma de elaboração da monografia de Silva (2008), entretanto, os estudantes que continuarem nivelados na Turma B deverão concluir o curso em 2009.2. Em qualquer caso, a análise dos dois primeiros semestres revela que a evasão permaneceu muita intensa apesar da mudança no Plano e Curso da Licenciatura em Geografia.
} 
Porque eu queria, tipo assim, ah passei no da UFRN, vou pagar minhas cinco disciplinas lá e umas três aqui, duas aqui, e indo, e indo e indo, e me formar os dois lógico. Só que aqui não permite entendeu? Tinha que pagar oito disciplinas, sete disciplinas e três, duas na UFRN [...] ( Entrevistado 06 - Turma B)

Aqui cabe questionar: será que a evasão se deu pelo regime de matricula ser por bloco de disciplinas ou pelo fato dos estudantes estarem fazendo dois cursos ao mesmo tempo? Fica a dúvida, pois, se por um lado a matrícula por créditos viabilizaria, segundo dois entrevistados, a permanência dos que possuem dupla matrícula e dos estudantes-trabalhadores, já que poderiam fazer seu próprio horário, por outro lado, alguns entrevistados afirmam que o regime de matrícula por crédito acabaria por incentivar a dupla matrícula, o que, a longo prazo, aumentaria a evasão, como afirma (Entrevistado 06 - Turma A):

"Mas é serio, que eu acho que o que a gente tava falando aqui é uma forma de pensar ou não de botar crédito. Porque sabe que no momento que botar credito todo mundo vai querer fazer CEFET e UFRN [...]"

Sobre a dupla matrícula é preciso levar em consideração que em um país no qual a maioria esmagadora de estudantes da educação superior está na iniciativa privada exista elevada incidência de dupla matrícula nas instituições públicas de educação superior e, além disso, que entre os que se encontram nessa situação seja elevada a evasão. Igualmente inquietante é o fato de que apenas a minoria dos estudantes-trabalhadores conseguem à educação superior e que, dentre eles muitos não consigam concluir a carreira na qual ingressaram.

Quanto à percepção dos estudantes acerca da profissão docente, apenas 2 afirmam ter abandonado o curso por esse motivo, por não quererem ser professores. Um deles alegou não ter vocação para tal profissão.

Porque eu pensei o seguinte: eu não tenho propósitos no curso de Geografia, então não adiantava eu me sacrificar, porque realmente era um sacrifício assistir aula de manhã, tarde e a noite, seria Geografia à noite, seguir um curso pra [...] mesmo que fosse bom, que eu gostasse, dentro da área de humanas, mas não faria sentido seguir um curso que eu não tinha propósitos né? Eu não teria esse desejo de ser professora né? (Entrevistado 01 - Turma B)

Os motivos de ordem socioeconômica e pessoal foram os que tiveram maior incidência. Dos dez entrevistados, oito citaram problemas socioeconômicos e pessoais como fator de maior peso para a saída do curso.

Em relação aos professores também eram ótimos, os meus professores do primeiro período foram ótimos também, o problema foi mais comigo, assim a minha visão que eu tinha, porque eu não tinha propósitos na área pedagógica, de professor, era mais na área de concursos, então como eu me frustrei, assim por não ter passado em psicologia prestei pra [...] aí eu pensei vou prestar pra Geografia, tendo em vista que é um curso bom e que também que eu vou ter um curso superior, então vou prestar esse vestibular e caso eu passe vou cursar, mas vou tentar uma última vez o outro 
curso, que foi nessa última vez eu passei. [...] tenho desejo de ser outra coisa que é na área de psicologia [...] (Entrevistado 01 - Turma B)

Primeiro porque [...] assim eu sempre gostei mais de História, eu sempre tentei Direito, sempre gostava dessas matérias, História, Geografia. Segundo por causa da Universidade Federal, a UFRN[...] e também, a terceira, foi influência do meu pai na época [...] que era pra eu fazer na federal. (Entrevistado 04 - Turma B)

Foram questões pessoais mesmo, assim o curso eu gostei muito, mas eu vi que não era exatamente com isso que eu queria trabalhar. Eu tava muito cansada, aí vem a parte de tensão mesmo. Eu tava muito sobrecarregada, muitas tarefas ao mesmo tempo e eu é normal eu me estressar, eu me aperrear, então [...] assim o curso tinha uma carga muito grande nesse lado, meu estresse, meu cansaço, boa parte era por causa do curso, e isso foi juntando, isso com outras coisinhas, aí eu vi que eu tinha que parar um pouco. Naquele momento, na hora que eu parei, eu achei que era hora de parar um pouquinho mesmo se não eu não ia agüentar [...] (Entrevistado 05 Turma A)

O que mais pesou? No momento foi a localização da faculdade. Porque eu passei nos dois vestibulares numa época só. O único fator foi esse, porque eu não podia optar [...] porque a UERN era a noite e o CEFET também a noite, a questão de eu morar bem pertinho da UERN [...] foi comodidade mesmo. (Entrevistado 06 Turma B)

No meu caso foi porque eu passei no vestibular da Universidade pra Pedagogia e era uma coisa que eu tava querendo muito [...] assim [...] que dentro de Geografia eu percebi que eu realmente queria uma coisa pra estudar o ensino mesmo, mais profundamente. E no meu caso teve a questão da minha sogra ter tido metástase de câncer de mama, e isso de certa forma, me fez decidir sair do CEFET. Eu até me arrependo, eu depois pensando que eu não deveria ter saído, mas assim [...] a gente ia muito pro hospital,então não tinha como eu me dedicar a dois cursos. (Entrevistado 07 - Turma A)

O fato de eu não querer estudar naquele momento, não era um projeto meu, era uma coisa da minha família, e o fato também do trabalho, na época a prioridade minha era trabalhar, era ganhar dinheiro, era sair de casa, era uma ânsia assim de sair de casa impressionante, e eu queria trabalhar pra poder conseguir sair de casa, e o estudo tava atrapalhando e eu não pensei duas vezes [...] ( Entrevistado 08 - Turma A)

eu tava trabalhando num projeto aí num escritório, eu tava dando assessoria às prefeituras dos interiores, então eu saia depois do almoço, meio dia, aí pra voltar era caixão...aí eu perdia muita aula. Aí resultado, eu acabei deixando mesmo [...] (Entrevistado 10 - Turma B)

Conclui-se que, segundo os estudantes, os motivos da evasão estão mais concentrados nos aspectos socioeconômicos e pessoais.

Diante das respostas dos estudantes é necessário ouvir os professores, dentre os quais também prevaleceu a idéia de que são os aspectos socioeconômicos e pessoais que têm relação mais direta com a evasão. Entretanto, os docentes também comentaram algumas questões relativas à representação dos estudantes em relação à profissão docente, com destaque para os itens: "O aluno não se identificar com a carreira docente em geral e, em particular, de Geografia”, e "O 
aluno fazer o curso apenas para ter um diploma”, o que também foi citado pelos alunos entrevistados.

Outros aspectos que, para os professores, podem ser considerados fatores de evasão são "o aluno fazer o curso somente enquanto não passa num concurso ou outro curso da UFRN”; "Alunos com duas matrículas e não tem tempo pra se dedicar, dando preferência ao outro curso".

Em síntese, foi possível observar que as contribuições dos professores ratificam o posicionamento dos estudantes.

\section{CONSIDERAÇÕES FINAIS}

A essa última parte do texto, será incorporada uma revisão sintética das principais causas de evasão detectadas pelo estudo. Assim, ao se analisar e contrastar as informações prestadas pelos estudantes e pelos professores, chega-se à conclusão que as causas indicadas como determinantes da evasão foram em ordem decrescente: as questões socioeconômicas $e$ pessoais (90\%); a instituição (20\%) e a profissão docente (20\%).

O estudo ratifica o fato de que o fenômeno da evasão não pode ser encarado como um fato isolado. Ele engloba uma série de fatores, externos e internos, que estão na vida do estudante. A decisão de persistir ou não no curso depende dos custos e benefícios associados à decisão.

Dentro da categoria questões socioeconômicas e pessoais, conclui-se que a dificuldade de conciliar a jornada de trabalho e o horário escolar é fator de suma importância na decisão de abandonar o curso. Também se observou que quando o aluno que é aprovado em concurso para ocupar cargo público deixa os estudos são para depois. Também é alta a incidência de estudantes que começam uma carreira querendo estar em outra. Assim, quando conseguem ingressar na carreira pretendida abandonam a anterior ou tentam fazer as duas, mas em geral acabam abandonando uma delas, geralmente, a primeira.

Quando se trata de problemas familiares os estudos também ficam em segundo plano. Um entrevistado quando se viu diante de um problema familiar optou por deixar o curso para dar atenção necessária a um familiar que se encontrava hospitalizado. São diversas situações como as citadas acima, motivos pessoais, que podem fazer parte do cotidiano de todos os alunos.

Os 20\% que culpabilizaram a Instituição, CEFET-RN, como a causa da saída do curso, afirmaram que a Instituição deveria oferecer o regime de matricula por crédito e não por bloco de disciplinas (módulo). Entretanto, algumas falas ressaltam, que a implantação do regime de matrícula por disciplina (créditos) implicariam no aumento da dupla matrícula entre CEFETRN e UFRN, o que implicaria em novas evasões.

Cada curso perde alunos por razões peculiares, e infelizmente a visão que alguns licenciandos têm sobre a profissão docente não é boa, tanto pela visão pouco positiva das perspectivas do mundo do trabalho como pelo prestígio profissional. Alguns desistem por falta de identidade com a profissão docente, de maneira que avançam no curso até o momento que precisam 
vivenciar em sala de aula aquilo que será sua profissão. É nessa hora que desistem, por descobrirem que não era isso o que queriam.

Pode-se pensar que a Instituição já fez sua parte quando modificou o Plano do Curso, alterando horário, matriz curricular, carga horária, entre outros aspectos. Entretanto, de acordo com o que foi dito pelos entrevistados no decorrer desse trabalho, o problema da evasão no CEFET-RN vai além das paredes da Instituição, de maneira que essas alterações melhoram o curso, mas não contribuíram para diminuir a evasão.

Nessa perspectiva, sugere-se que o CEFET-RN, por meio dos professores, coordenadores e equipe pedagógica, planeje e execute um processo de acompanhamento sistemático sobre os motivos das ausências reiteradas de estudantes, pois em geral, a evasão vem sendo construída ao longo do tempo e as ausências reiteradas são indicadores importantes desse processo. Concomitante a isso é importante buscar soluções para as distintas dificuldades encontradas pelos estudantes, quer seja de esclarecimento, motivação, horários, e até mesmo ir à busca desse estudante que se ausenta de forma reiterada, pois em várias entrevistas sujeitos evadidos afirmaram que estavam arrependidos da evasão e afirmaram que se pudessem voltariam à Instituição.

\section{REFERÊNCIAS}

BONFIM, M. I. R. M. A formação docente nos centros federais de educação tecnológica: diagnóstico sobre a oferta de licenciaturas pelos CEFETs. Brasília, DF: Abril, 2004.

BRASIL. Instituto Nacional de Estudos e Pesquisas Educacionais Anísio Teixeira (INEP). Censo da Educação Superior 2006. disponível em: http://www.inep.gov.br/superior/censosuperior/sinopse/. Acesso 15 abr. 2008.

Centro Federal de Educação Tecnológica do Rio Grande do Norte. Curso superior de licenciatura em geografia: plano de curso Reformulação Curricular. Aprovado pela Resolução nº 05/2006- Conselho Diretor/CEFET-RN, de 26/04/06. Natal-RN.

Curso superior de licenciatura em geografia: plano de curso. Autorizado pela

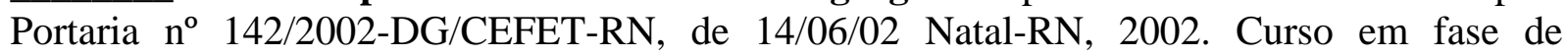
reconhecimento.

.Redimensionamento do Projeto Político-Pedagógico do CEFET-RN: Ponto de Partida. Grupo de trabalho instituído pela portaria $n^{0}$ 228/2003 - GD/CEFET-RN. Natal-RN, 2003.

GAIOSO, Natália Pacheco de Lacerda. O Fenômeno da evasão escolar na educação superior no Brasil. Brasília [s.n], 2005.

LAKATOS, Eva Maria. Fundamentos de Metodologia Científica. $5^{\mathrm{a}}$ ed. São Paulo: Atlas, 2003.

MOURA, Dante Henrique. Investigando a evasão nas licenciaturas oferecidas pelo CEFET-RN. Projeto de pesquisa apresentado e aprovado no âmbito do Edital No 02/2007 Programa de Apoio Institucional à Pesquisa e Extensão/CEFET-RN. Natal: mimeo, 2007. 
PENIN, Sonia Terezinha. Acompanhamento da trajetória escolar dos alunos da Universidade de São Paulo (USP) ingressantes de 1995 a 1998. Relatório Final. São Paulo, 2004.

RUIZ, Antonio Ibañez. Escassez de professores no Ensino Médio: propostas estruturais e emergenciais. $\quad$ Brasília, 2007. Disponível em: <http://portal.mec.gov.br/cne/arquivos/pdf/escassez1.pdf > Acesso 22. set. 2007.

SILVA, Meyrelândia dos Santos. Investigando a evasão no curso de Licenciatura em Geografia oferecido pelo CEFET-RN. 2008. Monografia (Graduação em Licenciatura em Geografia) - Centro Federal de Educação Tecnológica do Rio Grande do Norte. Natal: 2008.

VELOSO, Tereza C. M. A. Evasão nos cursos de graduação da Universidade Federal de Mato Grosso, campus universitário de Cuiabá - Um processo de exclusão. Disponível em: <http://www.anped.org.br/reunioes/24/T1142041450508.doc> Acesso 13.mar. 2008. 